\title{
The Case for Market Inefficiency: Investment Style and Market Pricing\#
}

\author{
Ron Bird* \\ Xue-Zhong He \\ Satish Thosar \\ University of Technology Sydney \\ Paul Woolley \\ GMO (Europe)
}

\begin{abstract}
Perhaps the most important consequence of pricing efficiency is its implications for the allocation of scarce capital resources. The proposition being that the higher a company's stock price, the easier access that it has to capital at a favourable cost. We have recently experienced an extended run up in stock prices in many markets amounting to what many would describe as a "bubble" that was followed by a major correction. Such market behaviour would appear to be consistent with many of the market anomalies that have been identified in markets and has led many to have reservations about the existence of efficient pricing. In this paper we examine the conditions that would lead to efficient pricing and question the extent that these conditions exist even in the most developed markets. In particular, we highlight a general move in markets towards two investment styles, index investing and momentum investing, where investments decisions are made without any reference to fair value. In order to further investigate the implications of such investment styles for security pricing, we model pricing behaviour in markets with different compositions of fundamental, momentum and index investors. We find evidence to suggest that compositions that are fairly typical of the mix of investors in current day markets will lead to price behaviour similar to that found by other writers: an underreaction to new information followed by an overreaction. This suggests that without any major change in the composition of styles followed by investors, we will continue to see evidence of market anomalies into the future and pricing bubbles particularly at times when we experience highly correlated information signals. Further, there would seem to be no natural end to this types of pricing behaviour as both momentum and index investing remain imminently sensible strategies to pursue from the perspective of the individual investor.
\end{abstract}

Corresponding Author: $\quad$ PO Box 123 Broadway NSW 2007 Australia

Phone: +61296147716

Fax: +6129514 7711

Email: ronbird@uts.edu.au

\# The authors would like to thank GMO Woolley and the Business Faculty at the University of Technology Sydney for funding this research, and also Charles Viennet for his research and programming assistance. 
The Case for Market Inefficiency:

Investment Style and Market Pricing

\section{Section 1: Introduction}

One of the important conditions that are required to ensure efficiency in market pricing is that investors actively compete in the market based upon perceived mispricings. In such a world, it is assumed that prices are soon driven to their fair value or, at least, to a level where investors, based upon the available information set, cannot consistently identify stocks whose prices are at variance with fair value. Our focus in this paper is on investigating the potential for efficiency within markets where many market participants pursue an investment style that pays no attention to fair pricing. Index and momentum investing are two styles that have become increasingly more popular in recent years where the investment decisions are made with no reference to fair pricing.

Index investing actually stems from a belief that markets are efficient and so active management cannot add value. As a consequence it has become increasingly more popular to invest with the objective of replicating a particular market index. The investment decision under this investment style (whether it be implemented by full replication or some statistical matching process) is driven by the proportion that a particular stock represents of the index and pays no attention as to whether each particular stock is fairly priced. Momentum investing would also seem to have become increasingly more (overtly) popular in recent years. Momentum investing can come in various forms being motivated by different signals. Examples of such signals include investing in: (i) stocks whose prices have gone up rapidly in recent months, (ii) firms that have announced an earnings figure in excess of market expectations, (iii) stocks where a large number of analysts have increased their earnings forecasts. However, one important characteristic lacking in all of the decisions rules followed by the momentum investor is any reference to a stock's fair value. Whereas index investing is somewhat neutral in terms of its impact on current prices, momentum investing has the potential for accelerating any price trends that may well exacerbate any market mispricings.

It is important to consider the impact of the various popular investment styles on pricing given the ever increasing evidence on market anomalies and particularly the economic impact of bubbles, which may be one artefact of such anomalies. It may well be that that markets are becoming less efficient with changes in the composition of investors following disparate investment styles. In Section 2 of the paper, we review the literature both in terms of the development of different investment styles, and the growing evidence on market anomalies in order to provide insights into how investment styles may explain much of the behaviour that we currently see in markets. In Section 3, we specify the behaviour of the different types of investors in a way that enables us to model the pricing mechanism given different combinations of the various types of investing. The results of our Monte Carlo simulations are reported in Section 4 with special emphasis on the insights that they provide as to pricing which is related to evidence found elsewhere in the literature. We conclude in Section 5 with a summary of our findings and their implications, and discussion of possible directions for future research.

\section{Section 2: The Evidence on Market Behaviour}

The concept of the efficient pricing of securities has been around for over a century but it was both classified and popularised by the work of Fama just over 30 years ago (see Fama [1970]). In this section of the paper it is our intention to first review the conditions that underpin market efficiency and then consider the evidence on market anomalies with the overall objective of developing a case to support the proposition that many of the anomalies that have been observed in recent years can be attributed to departures from these conditions.

\section{Conditions for Market Efficiency}

Our starting proposition is that in an efficient market, securities are "correctly" priced to the extent that investors cannot use available information to formulate an investment strategy that consistently generates excess returns. For example, market efficiency assumes that strategies based upon such information as a firm characteristic (size), some valuation parameter (book-to-market) or some corporate announcement (a new 
share issue) cannot consistently generate returns over and above the level necessary to reward for the inherent risks of the investments.

We will discuss two broad assumptions that underpin the concept of efficiency as outlined above ${ }^{1}$ :

1. Availability of information: If the market is going to "correctly" price a security, then it is necessary that sufficient market participants have access to the relevant information in order to incorporate this information into their investment decisions and hence into the price of a security. For this to occur there has to be a ready flow of "unbiased" information from firms to the market in order to enable investors to make their assessment of the true value of a security. There is much literature in recent times that would question, at least, two aspects of information flows:

(i) The extent to which information freely flows from firms to the market: The issue here is whether there is a significant difference between the information known within a company and that which is known in the market (asymmetric information). There is a fair degree of circumstantial evidence given the extent to which market participants attempt to interpret the implications of every corporate announcement for the company's future earnings potential. The list is almost endless in terms of the types of announcement (e.g. earnings, dividends, share issues, share repurchases, share splits) to which the market reacts in a predictable way ${ }^{2}$.

(ii) The extent to which information provided to the market is manipulated: The prices set are not only related to the quantity of information provided to the market but also the veracity of that information. An obvious instance where this could be questioned is with accounting earnings where companies have options within accepted accounting principles for calculating the reported earnings figure. Available evidence would suggest that investors do not immediately see through any distortions due to accounting choice which provides companies with the opportunity to distort the price of their securities, at least in the short-term (Sloan [1996], Chan et al [2001]).. Of course, this is not the only form of possible manipulation as it is evident from previous discussion that a company via its announcements can signal information to the market. As such it has the opportunity to employ these signalling devices to send false signals to the market and hence distort the price of their securities. Finally, of course, there is the option of simply contriving information which again will have a short-term impact on security prices and there are some quite famous examples of this in recent times (e.g Enron).

2. The existence of a large number of rational, profit maximizing investors: The proposition here is that a large number of informed investors all trying to maximize their investment returns will quickly drive prices to a level that fully reflects all available information. As with information flows, there is a growing volume of literature which questions whether market participants are competitive to the extent required to ensure efficiency $^{3}$ :

(i) Principal/agency issues: Numerous articles have questioned whether important financial intermediaries are single-mindedly pursuing the maximisation of investment returns. Those intermediaries that most immediately come to mind here are analysts and investment managers. The principal/agency issues confronting the analysts are well documented and, along with their behavioural biases, have been suggested as explanations for why their forecasts and recommendations provide limited information and may even contribute to distortions in valuations rather than their correction (see for example, Jegadeesh et al [2004]). . Investment managers face similar conflicts between the interests of their clients and their own company and personal objectives where risk considerations may lead them to depart from a strategy solely directed to maximizing the wealth of their clients

(ii) Investment styles: One presumption is that the market is populated with investors whose investment decisions are geared to exploiting perceived market mispricings. As a consequence these investors play an

\footnotetext{
${ }^{1}$ We will not consider a third set of assumption relating to the existence of market imperfections such as taxes, brokerage and other costs which drive a permanent wedge between actual price and the fair price. Rubinstein [2001] defines a market as being minimally rational where such imperfections would result in no abnormal profitable opportunities being available.

${ }^{2}$ For a summary of some of this evidence see, Smith [1986]

${ }^{3}$ See De Long et al [1990] for a discussion of the possible destabilising influence of "positive feedback" investors.
} 
important role in ensuring market efficiency. Indeed in the very early days of the market efficiency literature, writers pointed out the obvious conundrum that the existence of efficient markets depends upon many market participants believing that active investment can add value (i.e. that markets are not efficient) (Lorie and Hamilton [1973]). Of course, over the last 30 years we have seen many investors turn to index investing fuelled by the presumption that markets are efficient and the evidence on the failure of the majority of active investment managers to outperform the major indices (Malkiel [2003]). The drift to index investing has resulted in upwards of $25 \%$ of many of the developed equity markets being in the hands of passive investors. However, the story does not end there as the movement to making active managers more accountable has resulted in many of them moving to being closet indexers with respect to a significant portion of their funds. Therefore, it would not be unreasonable to assume that a third or more of the funds in many investment markets are subject to either overt or covert passive investing. What this effectively does is it takes a significant proportion of investible funds "out of the market" in that they are invested on the basis of the proportion that a particular stock represents of the index with no reference to valuation (Woolley and Bird [2003]).

Momentum investing is another style that has achieved prominence in recent years although it has undoubtedly been practiced even before index investing achieved any popularity. It has been demonstrated that momentum investing consistently generates excess returns suggesting a market inefficiency which has proved difficult to explain away using the traditional arguments (Jegadeesh and Titman [2001]). Momentum comes in various forms with it being measured using past price movements, past returns, earnings changes or changes in analyst forecasts. It has been documented that analysts favour high momentum stocks when making their investment recommendations (Jegadeesh et al [2004]), while it is inherent in the investment process of a significant proportion of money managers (Burch and Swaminathan [2001]). In many markets, momentum investing would play a role in the management of upwards of $50 \%$ of the actively managed funds. As such this represents another large proportion of the market that is in the hands of investors who make no reference to valuation when making their investment decisions and so play no role in correcting any market mispricings. Indeed, such forms of investment are generally destabilising rather than stabilising as they serve to exacerbate trends that already exist in markets.

The impact of index and momentum investing on the pricing behaviour of markets will be the major focus in this paper. We are particularly interested in the impact that the pursuit of these investment styles has when they represent a significant proportion of markets and especially whether they contribute even a partial explanation for many of the identified anomalies.

\section{Evidence on Market Anomalies}

For the first several years after Fama [1970] codified the Efficient Markets Hypotheses, there was a strong flow of empirical evidence that was interpreted as supportive of at least the semi-strong version of the EMH. However over the most recent 25 years, we have seen a mounting volume of evidence to question market efficiency at all levels which has fuelled the debate as to whether even the most developed and regulated markets can really be assumed as being efficient. The objective in this part of the paper is to provide a brief summary of the evidence on market anomalies under three headings:

(i) Firm characteristics: Starting in the mid-60's, writers have found that firm characteristics such as book-tomarket, price-to-earnings, size, sales growth and many others are correlated with future market performance (Lakonishok, Shleifer and Visny [1994]). As Fama [1998]) has pointed out, it is not surprising that at any point in time the methodology that we use to undertake such studies will identify such anomalies but what is harder to explain is the persistence of these correlations both through time and across markets.

(ii) Market behaviour: A number of writers have identified some association between market performance of a stock over some past period and its performance in the more immediate future. De Bondt and Thaler [1985] found that stocks that performed well (poorly) over an extended period of time tended to under- (over-) perform thereafter. In contrast Jegadeesh and Titman [1993] found that stocks that had performed well in the immediate past tended to perform well in the immediate future. In particular, the latter finding has been found to persist through time and across markets and as such has been a major catalyst for the increase in the 
popularity of price/return momentum investing. In a similar vein, many writers have found that the existence of a post-earnings announcement drift in prices which means that the price of companies with good (bad) earnings announcement tends to drift upwards (downwards) after announcements where good or bad is relative to some base such as last years earnings or the market's expectations as proxied by the consensus earnings forecasts of the analysts.

(iii) Corporate announcements: Numerous studies have found a predictable market response to many types of corporate announcements relating to events such as new share issues, share repurchases, stock splits, dividend changes and insider trades. For example a new share issue is usually a bad sign and results in the fall in a firms' share price but a share repurchase has the opposite effect (Harris [2004], Ikenberry et al [2000]). However, one thing that is common to all of these announcements is that the market reaction is not instantaneous but rather is the catalyst for a drift in prices which can extend up to several years.

\section{Implications of Evidence}

There is an on-going debate, especially in academic circles, as to the implications of the evidence on anomalies for market efficiencies. Arguments put forward to support efficiency in the face of the anomalous findings include that they can be explained by flaws in the methodology employed, a failure to control properly for risk, a failure to incorporate transaction costs, and/or simply that they were specific to the period of the study. The debate is on-going with somewhat surprisingly the opinion of the majority of the academic community being that markets are efficient and it is possible that this colours their own research and their interpretation of research done by others (Lee [2001]).

The focus of this study is to provide more food for thought to support the case that maybe markets are not efficient with the mix of investment styles that exist in the market being one important contributing factor to this outcome. However, before going on to consider this proposition over the remainder of the paper, it is important to draw some of the pricing implications of the existing evidence on market anomalies:

(i) Prices will under-react to individual pieces of information but over-react to an aggregation of information: Many studies have highlighted a slow reaction in prices to information releases which in some instances would appear to extend over a number of years(Foster et al [1984]. In contrast the work of DeBondt and Thaler [1985] and others would suggest that prices often move to unsustainable levels from which they correct. This research has given rise to the apparent conundrum that prices would seem to both underreact and overreact to information. A number of behavioural explanations for this conundrum have been proposed ${ }^{4}$. The explanation provided by Hong and Stein [1999] is most in the sprit of our study in that they allow for two types of investors: news followers and trend followers. In their model, the release of good news attracts the selective interest of news followers and so a small adjustment in price (i.e. underreaction). Further releases of good news have a similar effect eventually leading to the development of a price trend which attracts the trend followers who feed a price spiral. Eventually a situation is reached where the information cannot justify the price level (overreaction) which causes some guarded selling by the news watchers but not sufficient to reverse the trend. A continuation of this bad news will not only cause the news watchers to reverse the price rise but eventually a reversal will reach a level that attracts the trend followers and so the over- and under-reaction continues.

Kadiyala and Rau [2001] have conducted an insightful study that suggests that the usual market response to individual announcements is under-reaction. Soffer and Walther [2000] have provided evidence suggestive of serial correlation in price movements being largely driven by serial correlation in announcements but with a lag which explains why the small initial price reaction is followed by over-shooting as the price continues to rise after the fundamentals of the company reverse.

(ii) Extended periods of time when a stock's price is removed from its fair value: We have already suggested that the stock price of companies will lag fair value in response to new information but potentially extend beyond fair value in the longer term. However, this does not address the issue of the extent to which prices

\footnotetext{
${ }^{4}$ Others included Barberis et al [1998] and Daniel et al [1998]
} 
will depart from fair value and, indeed, the likelihood that we will see "bubbles" in markets with sustained periods where stock prices differ by a large amount from fair value. It is difficult to be definite about whether the market's proclivity to experience bubbles is changing. However at a time when index and momentum investing were at a zenith, we recently experienced the longest market cycle ever in many countries with prices reaching extreme levels followed by a major correction Siegel [2003]. Perhaps this can be best seen in the relative performance of growth and value investing which became more volatile in the late 1990's at the height of the boom and in the early 2000's during the subsequent correction period. It may well be that we will continue to see relatively volatile markets going forward with extremes of pricing if the current trend towards index and momentum investing is not reversed. This may prove to be a major concern to regulators given the potential of bubbles to result in major misallocations of resources and for the corrections to cause a loss in confidence which has a long-term effect on markets.

\section{Section 3: Methodology}

The approach that we take in this paper is to model the market behaviour of different types of investors in order to investigate the pricing implications of various combinations of these investors operating in the market. In this section of the paper we outline the basis for our model that incorporates three types of investors:

- Fundamental investors who trade on the basis of the difference between a stock's current price and its perceived fair value

- Momentum investors who trade upon price movements over some prior period

- Index investors who simply trade to replicate the market index

\section{Initial Set Up}

Our aim is to create a market with sufficient complexity to provide us with interesting insights into to pricing behaviour and this is achieved by restricting our analysis to a market with the following characteristics:

- one stock (which could be an index) and one risk free asset

- the risk free asset is perfectly elastically supplied at a gross return of $R=1+r / K$, where $r$ stands for a constant annual risk-free rate ${ }^{5}$ and $K$ stands for the frequency of trading period per year which is assumed to be weekly (thus $K=52$ periods per annum)

- The sole source of information that affects prices are quarterly earnings announcements where the quarterly growth in earnings is:

- either randomly drawn each quarter from a distribution with an assumed mean of $1 \%$ and a standard deviation of $2 \%$, or

o serial correlation is built into the earnings growth by assuming that

- there is a positive serial correlation over the first 6 quarters: the draw at $t$ is the mean value for the draw at $t+1$;

- over the following 6 quarters, growth follows a mean reversion process: the mean of the draw at $t+1$ is the average of the draw at time $t$ and $1 \%$ which is the assumed longterm average;

- this 12 quarter cycle is then repeated.

- After each quarterly earnings announcement, a new fair value for the stock is determined by applying a dividend discount model as described below and a new round of weekly trading is generated ${ }^{6}$

\footnotetext{
${ }^{5}$ This could be modeled to follow some stochastic process.

${ }^{6}$ For simplicity, it is assumed that the fair value is equal to the fundamental value as determined by the fundamental investors.
} 


\section{Determination of Fundamental Value}

The fundamental investors determine a new fundamental value for the stock immediately after each earnings announcement by extrapolating out the earnings growth for the next 12 quarters at the average earnings growth rate for the current and the previous three quarters. These projected earnings figures are then used in a dividend discount model at a risk-adjusted rate to determine the fundamental price.

Some of the notation for determining the fundamental value is set out below:

- $P_{t}$ : the stock price (ex dividend) per share at time (week) $t$;

- $\quad E_{T}$ : the earning per share of the stock over the quarter $T$;

- $g_{T}$ : growth rate of the earning over the quarter $T$;

$$
E_{T}=\left[1+g_{T}\right] E_{T-1} .
$$

Say, for example, earnings have been growing at $g=1 \%$ per quarter for the last $n$ quarters

- Earnings at quarter $T$ (just announced): $\$ 1$;

- Earnings at quarter $T-1: \$ 0.9904=1 /(1+g)$;

- Earnings at quarter $T-2: \$ 0.9803=1 /(1+g)^{2}$;

- Earnings at quarter $T-3: \$ 0.9706=1 /(1+g)^{3}$;

- And so on.

- $D_{T}$ : the dividend paid per share of the stock over the quarter $T$;

- $\lambda$ : the fixed payout rate:

$$
D_{T}=\lambda E_{T}, \quad \lambda \in[0,1]
$$

- $r_{t}$ : the required rate of return, or the cost of capital for the firm at time $t$;

- $\quad P_{t}^{*}$ : the fundamental price at time $t$ of the stock. For $t \in[T, T+1), P_{t}^{*}=P_{T}^{*}$.

- $F_{t}$ : the common information set formed at time $t:\left\{P_{t}, P_{t-1}, \cdots D_{T}, D_{T-1}, \cdots\right\}, t \in[T, T+1)$.

We will assume a payout ratio of $\lambda=80 \%$. The fundamental stock price $P_{t}^{*}$ is fixed over each quarter

$$
P_{t}^{*}=P_{T}^{*}, \quad t \in[T, T+1) .
$$

It is calculated each quarter on the assumption that earnings will grow over the next 12 quarters at the average of the earnings growth rates over the current quarter and the last three quarters $\left(\bar{g}_{T}\right)$. Beyond the next 12 quarters it is assumed that the earnings will continue to grow at a constant $g_{0}=1 \%$ pa. The cost of equity capital for the stock is assumed to be $r=2 \%$ (fixed) per quarter.

Denote:

$$
\bar{g}_{T}=\frac{1}{4}\left[g_{T}+g_{T-1}+g_{T-2}+g_{T-3}\right]
$$

Then, the fundamental price will be given by 


$$
\begin{aligned}
P_{T}^{*} & =\lambda E_{T}\left(\sum_{i=1}^{12}\left[\frac{1+\bar{g}_{T}}{1+r}\right]^{i}+\sum_{i=13}^{\infty}\left[\frac{1+g_{0}}{1+r}\right]^{i}\right) \\
& =\lambda E_{T}\left[\frac{1+\bar{g}_{T}}{r-\bar{g}_{T}}\left[1-\left(\frac{1+\bar{g}_{T}}{1+r}\right)^{12}\right]+\frac{1+r}{r-g_{0}}\left(\frac{1+g_{0}}{1+r}\right)^{13}\right]
\end{aligned}
$$

As a special case when $\bar{g}_{T}=g_{0}$, we obtain the Gordon valuation formula

$$
P_{T}^{*}=\lambda \frac{1+g_{0}}{r-g_{0}} E_{T}
$$

For example, if $\bar{g}_{T}=g_{0}=1 \%, r=2 \%$,

$$
P_{T}^{*}=\lambda \frac{1+g_{0}}{r-g_{0}} E_{T}=\$ 0.80 \frac{1+0.01}{0.02-0.01}=\$ 80.80 .
$$

\section{Heterogeneous Trading Strategies}

As we mentioned early, in this paper, we assume that there are three types of investors: fundamental, momentum and index investors. In the following discussion we outline the nature of the demand function for each of the three types of investors.

1 Fundamental Investors: For the fundamental investors, we make the following assumptions. Firstly, they believe that the market price is mean reverting to their perceived fundamental price and they purchase (sell) the stocks when the market price is below (above) their perceived fundamental price. Secondly, they trade only when the current price deviation from the fundamental price $P_{t}-P_{t+1}^{*}$ is either above or below a certain percent, say $\bar{\alpha}_{f} \in[0,1]$, of the current price level so that to compromise their risky investment and various costs, such as trading cost and interest. Thirdly, given their role in stabilizing the market, their demand is proportional to the deviation of the market price from the fundamental price. Based on these assumptions, the demand of the fundamental investors $z_{f, t}$ at time $t$ may be defined by the following piece-wise linear function

$$
z_{f, t}=\left\{\begin{array}{lll}
\alpha_{f}\left[P_{t+1}^{*}-\left(1+\bar{\alpha}_{f}\right) P_{t}\right] & \text { if } & P_{t+1}^{*}>\left(1+\bar{\alpha}_{f}\right) P_{t} \\
0 & \text { if } & \left|P_{t+1}^{*}-P_{t}\right|<\bar{\alpha}_{f} P_{t} \\
\alpha_{f}\left[P_{t+1}^{*}-\left(1-\bar{\alpha}_{f}\right) P_{t}\right] & \text { if } & P_{t+1}^{*}<\left(1-\bar{\alpha}_{f}\right) P_{t} .
\end{array}\right.
$$

where

- $P_{t}^{*}=P_{T}^{*}$ for $t \in[T, T+1)$;

- $\alpha_{f}>0$ measures the demand intensity;

- $\bar{\alpha}_{f}>0$ measures the required risk premium to cover the total cost, including the capital cost and transaction cost, etc..

The demand function defined indicates that the fundamental traders only take long (short) position when they believe the gain (loss) of the market price from their perceived fundamental price is above (below) $\bar{\alpha}_{f}$.

2. Momentum Investors: The basic approach taken by momentum investors is to purchase (sell) stocks that have risen in price over the previous 13 weeks by an amount greater (less) than $g_{o}=1 \%$, which is the average growth rate per quarter, and to hold the position created for 13 weeks before reversing it. This is akin 
to the trading strategies set out in Jagadeesh and Titman [2001] with a 13-week formation period and a 13week holding period. More precisely, for the momentum investors, we assume that

- their trading signals are generated by the difference between the current price and the price in 13 weeks previously accumulated at the rate $g_{o}=1 \%$; that is

$$
P_{t}-\left(1+g_{o}\right) P_{t-13}
$$

- they take a long (short) position only when the return generated from the difference is above (below) certain percent, say $\bar{\alpha}_{m} \in[0,1]$, which measures the cost. That is, they take long position when

$$
\frac{P_{t}-\left(1+g_{o}\right) P_{t-13}}{\left(1+g_{o}\right) P_{t-13}}>\bar{\alpha}_{m}
$$

and take short position when

$$
\frac{P_{t}-\left(1+g_{o}\right) P_{t-13}}{\left(1+g_{o}\right) P_{t-13}}<-\bar{\alpha}_{m} .
$$

- they are risk averse. They increase their (long/short) positions initially when the trading signals generated are strong enough. However, they are cautious when such signals are too strong. That is, their demand function is a nonlinear increasing function of the trading signals, but the marginal demand function is decreasing.

- they hold their positions for 13 weeks and then reverse them.

Based on the above assumptions, the demand function of the momentum investors $z_{m, t}$ at time $t$ may thus be defined by

$$
z_{m, t}= \begin{cases}\bar{z}_{m, t}, & t=1,2, \cdots, 13 \\ \bar{z}_{m, t}-\bar{z}_{m, t-13} & t>13,\end{cases}
$$

where the demand function $\bar{z}_{m, t}$ at time $t$ is defined by the following piece-wise nonlinear function

$$
\bar{z}_{m, t}=\left\{\begin{array}{lll}
\alpha_{m} \tanh \left(\frac{\beta_{m}}{\sigma^{2}}\left[P_{t}-\left(1+\bar{\alpha}_{m}\right)\left(1+g_{o}\right) P_{t-13}\right]\right) & \text { if } & P_{t}>\left(1+\bar{\alpha}_{m}\right)\left(1+g_{o}\right) P_{t-13} \\
0 & \text { if } & \left|P_{t}-\left(1+g_{o}\right) P_{t-13}\right|<\alpha_{m}\left(1+g_{o}\right) P_{t-13} \\
\alpha_{m} \tanh \left(\frac{\beta_{m}}{\sigma^{2}}\left[P_{t}-\left(1-\bar{\alpha}_{m}\right)\left(1+g_{o}\right) P_{t-13}\right]\right) & \text { if } & P_{t}<\left(1-\bar{\alpha}_{m}\right)\left(1+g_{o}\right) P_{t-13},
\end{array}\right.
$$

where

- $\alpha_{m}>0$ measures the demand intensity;

- $\sigma^{2}>0$ measures the volatility of the market price, which is assumed to be a constant;

- $\bar{\alpha}_{m}>0$ measures the trading cost;

- $\quad \beta_{m}$ measures how quickly the traders adjust their demand when the trading signals are small.

3. Index Investors: In the current setting, the risky asset is treated as the index. Hence, the demand of the index investors $z_{i, t}$ is zero. That is,

$$
z_{i, t}=0 \text {. }
$$




\section{Market Fractions}

Let $N$ be the total number of traders, among which, there are $N_{f}$ fundamental investors, $N_{m}$ momentum investors and $N_{i}$ index investors. Within each style of investing, the investors have the same demand function. The market fractions of traders are defined by

$$
n_{f}=\frac{N_{f}}{N}, \quad n_{m}=\frac{N_{m}}{N}, \quad n_{i}=\frac{N_{i}}{N}, \quad N_{f}+N_{m}+N_{i}=N
$$

We evaluate a number of test cases where it is assumed the market is composed of fixed proportions of the three types of investors ${ }^{7}$. Based on the previous discussion, the excess demand of the risk asset $z_{e, t}$ at time $t$ is then given by

$$
z_{e, t} \equiv n_{f} z_{f, t}+n_{m} z_{m, t}+n_{i} z_{i, t}
$$

where $z_{f, t}, z_{m, t}$ and $z_{i, t}$ are the demand functions defined in (3), (4) and (5), respectively.

\section{Market Maker and Market Clearing Price}

Apart from the three types of investors discussed, we introduce a market maker to clear the market. The role of the market maker is to take a long position (when $z_{e, t}<0$ ) or a short position (when $z_{e, t}>0$ ) so as to clear the market. At the end of period $t$, after the market maker has carried out all transactions, he or she adjusts the price for the next period in the direction of the observed excess demand. Using $\mu$ to denote the corresponding speed of price adjustment of the market maker towards the excess demand from all three types of investors. Then the market-clearing price at time period $t+1$ via the market maker scenario would be given by:

$$
P_{t+1}=P_{t}+\mu z_{e, t}
$$

It follows from (7) and (8) that the market clearing price is governed by

$$
P_{t+1}=P_{t}+\mu\left[n_{f} z_{f, t}+n_{m} z_{m, t}+n_{i} z_{i, t}\right],
$$

where $z_{f, t}, z_{m, t}$ and $z_{i, t}$ are defined in (3), (4) and (5), respectively.

The market maker behaviour in this model is highly stylised. For instance, the inventory of the market maker built up as a result of the accumulation of various long and short positions is not considered. This could affect his or her behaviour, e.g. the market maker price setting role in (9) could be a function of the inventory.

\section{Section 4: Findings}

As we saw in Section 2, market efficiency is largely dependent on competition between investors - each attempting to maximize their investment returns by identifying mispriced stocks. We went on in this section to suggest that a likely reason for the many anomalies that have been identified in markets is the fact that an increasing proportion of markets are now dominated by index and momentum investors who pay no attention to valuations when making their investment decisions. In Section 3, we developed a model composed of fundamental, index and momentum investors to allow us to simulate pricing behaviour within a market composed of these three types of investors. The focus in this section is to vary the composition of markets by changing the proportions that each type of investor represents in the market in order to examine the resulting price behaviour, especially in terms of its implications for market efficiency. The various combinations of

\footnotetext{
${ }^{7}$ This can be relaxed by introducing certain performance measures and allowing investors to switch between investment styles over time.
} 
investors within the test cases that we examine are set out in Table 1. For each test case we ran 200 Monte Carlo simulations of the market behaviour over a period of 25 years.

For all simulations, we select parameters as follows:

$$
\lambda=0.8, \mu=1, \alpha_{f}=\alpha_{m}=\alpha_{i}=1, \beta_{m}=\sigma^{2}, \bar{\alpha}_{f}=\bar{\alpha}_{m}=\bar{\alpha}_{i}=0.03 / 12 .
$$

The initial prices are drawn from a normal distribution $N\left(P_{o}^{*}, 1\right)$ with $P_{o}^{*}=80.80$. The quarterly growth in earnings $g_{T}$ is normally distributed $N\left(g_{o}, \sigma_{g}^{2}\right)$ with $g_{o}=1 \%$ and $\sigma_{g}=1 \%$.

Table 1: Test Cases

\begin{tabular}{|c|c|c|c|}
\hline Test Case & Fundamental Investor (\%) & Index Investor (\%) & Momentum Investor (\%) \\
\hline 1 & 100 & 0 & 0 \\
\hline $2 \mathrm{~A}$ & 75 & 25 & 0 \\
\hline $2 \mathrm{~B}$ & 50 & 50 & 0 \\
\hline 2C & 25 & 75 & 25 \\
\hline $3 \mathrm{~A}$ & 75 & 0 & 50 \\
\hline $3 \mathrm{~B}$ & 50 & 0 & 75 \\
\hline $3 \mathrm{C}$ & 25 & 12.5 & 12.5 \\
\hline $4 \mathrm{~A}$ & 75 & 25 & 25 \\
\hline $4 \mathrm{~B}$ & 50 & 37.5 & 37.5 \\
\hline $4 \mathrm{C}$ & 25 & 33.33 & 33.33 \\
\hline $4 \mathrm{D}$ & 33.34 & & 0 \\
\hline
\end{tabular}

\section{Test Case 1: 100\% Fundamental Investors}

We assume that the fair value of a stock is set by the fundamental investor (as explained in the previous section). The moments of the weekly returns based on (i) the fair price, (ii) the price generated in the market entirely composed of fundamental investor and (iii) the difference between these two sets of prices, as obtained by averaging over the 200 simulations are reported in Table 2 . As one would expect, the generated price tracks the fair value very closely with only a slight lag caused by the fact that we only allow for weekly trading in our simulations. The results reported in Table 2 are for the case where earnings growth is assumed random but they remain basically unchanged when we build serial correlation into earnings growth as described in the previous section (Soffer and Walther [2000]).

Table 2: Fundamental Investors (Random earnings growth)

\begin{tabular}{|c|c|c|c|}
\hline \multirow{2}{*}{ Moments } & Fair value & Fundamental investor & $\begin{array}{c}\text { Difference between } \\
\text { fundamental returns } \\
\text { and fundamental } \\
\text { returns }\end{array}$ \\
\cline { 2 - 4 } & 0.000755 & 0.000762 & 0.00007 \\
\hline Mean & 0.004571 & 0.00404 & 0.000551 \\
\hline Standard deviation & 4.41703 & 4.77505 & 4.7751 \\
\hline Skewness & 30.0242 & 34.9662 & 145.2844 \\
\hline
\end{tabular}




\section{Test Case 2: Fundamental and Index Investing}

In test cases $2 \mathrm{~A}, 2 \mathrm{~B}$ and $2 \mathrm{C}$ we examine the implications for pricing of various combinations of fundamental investing with index investing, where earnings growth through time is random. We report in Table 3 , the moments of the differences in returns between the generated returns and the fair value returns for each of the test cases. The critical impact of introducing index investors into the market is that they are oblivious to new information becoming available and so one might expect an increasing incidence of index investors to progressively slow the price adjustment process as fair value changes. From the information presented in Table 3, we do see evidence to support this proposition as the tracking error of each of the test cases (the standard deviations of the difference in the returns) increases with an increase in the percentage that index investors represent of the market. Further, the fact that the difference between these returns is negatively skewed suggests that for the majority of trading periods the generated prices are underperforming fair value which in turn suggests that these generated prices frequently trail fair value. Importantly, this is borne out by the serial correlation patterns reported in Figure 1 which clearly indicates a slower response to information with an increased presence of index investors. Again this is seen in Figure 2 where we plot a slice of our history of the fair value price and the generated prices under test case $2 \mathrm{~B}$ where we have $50 \%$ fundamental investors and $50 \%$ index investors ${ }^{8}$.

Table 3: Fundamental and Index Investors (Random earnings growth)

\begin{tabular}{|c|c|c|c|}
\hline \multirow{2}{*}{ Moments } & \multicolumn{3}{|c|}{ Returns relative to fair value returns for various test cases: } \\
\cline { 2 - 4 } & $25 \%$ index inv. (2A) & $50 \%$ index inv. (2B) & 75\% index inv. (2C) \\
\hline Mean & 0.000007 & 0.000007 & 0.00007 \\
\hline Standard deviation & 0.00149 & 0.00252 & 0.00344 \\
\hline Skewness & -1.2304 & -2.6875 & -3.8785 \\
\hline Kurtosis & 18.5860 & 20.2363 & 26.0150 \\
\hline
\end{tabular}

\footnotetext{
${ }^{8}$ These price histories are for one of our simulations chosen on the basis that it portrays "median-type" characteristics based on our 200 simulations
} 
Figure 1: Serial Correlation Patterns with Index Investors (random earnings growth)
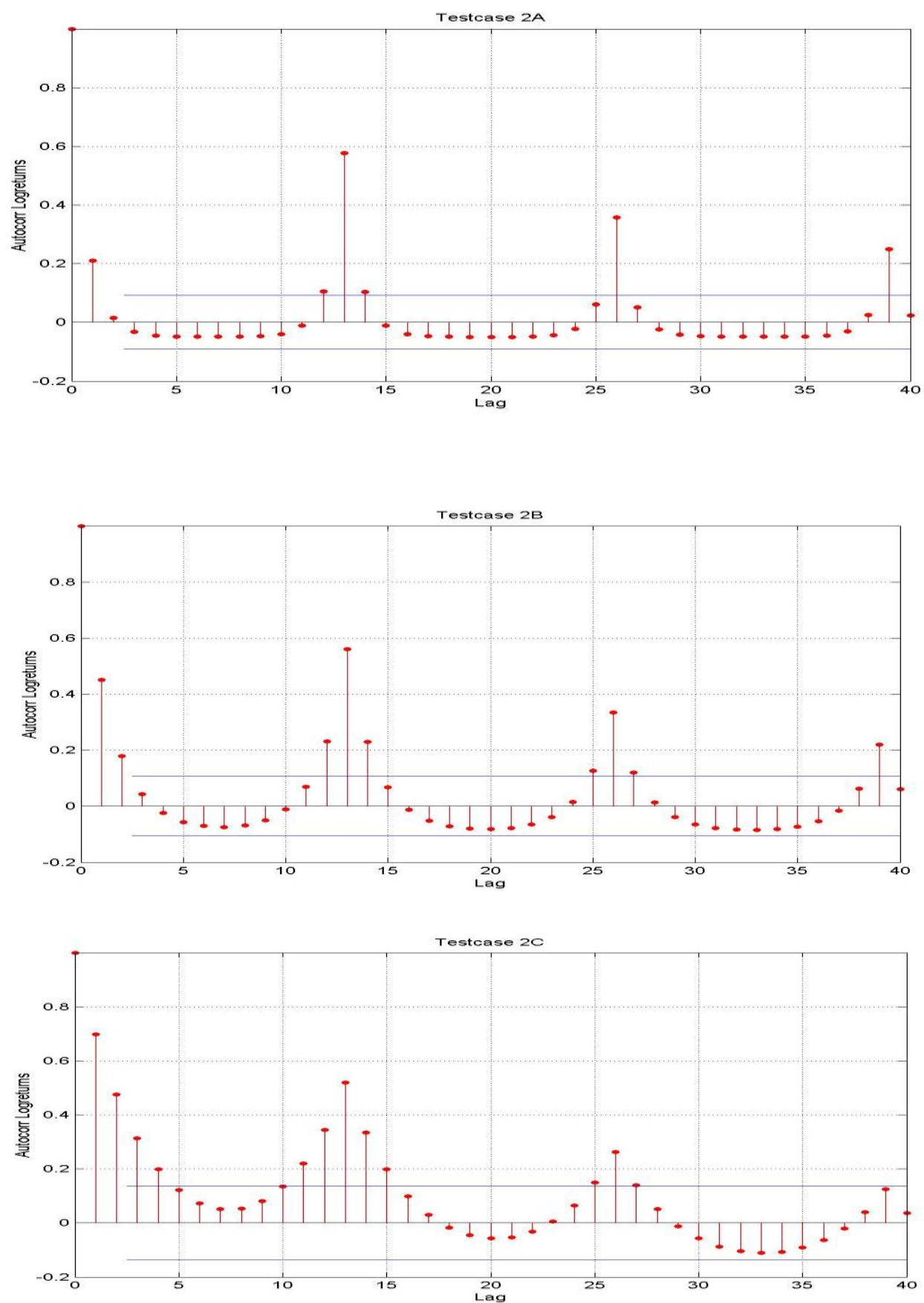
Figure 2: Test Case 2B Price Chart (random earnings growth)

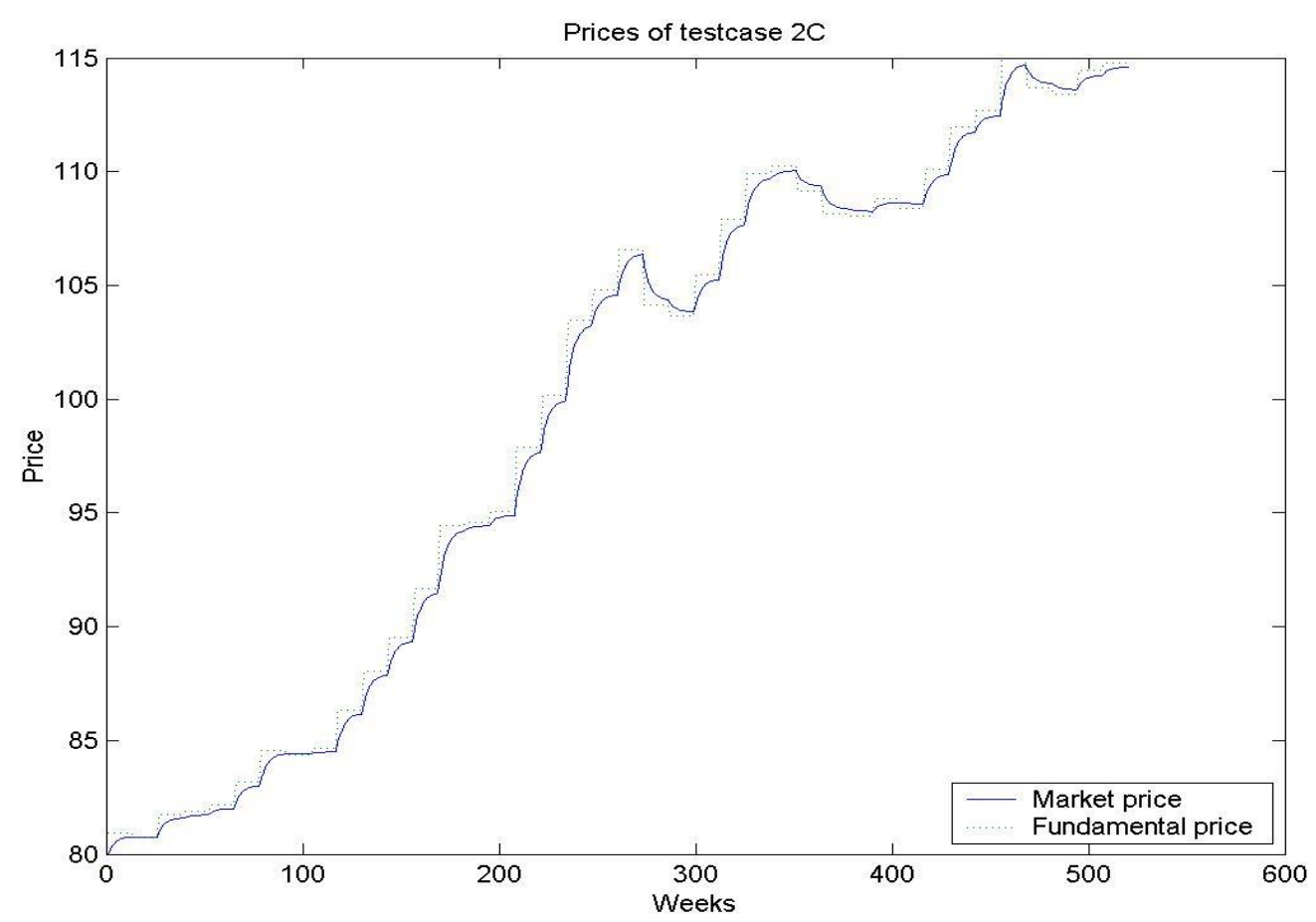

We now consider the impact of index investors where we build serial correlation and then mean reversion into our pattern of earnings (and so fair value) growth. The moments of the distribution of the fair value prices are set out in the second column of Table 4. A comparison of these moments to those where earnings growth was random (column 2 of Table 2) highlights that each moment is higher with perhaps the most important being the volatility in prices as indicated by the standard deviation being one-third higher than was the case when earnings growth was randomly generated. A similar comparison of the other information presented in Table 4 with that presented in Table 2 indicates that both tracking error and skewness increases with the changed pattern for generating earnings growth, which further indicates that generated prices lag fair value more under this new scenario. An examination of the serial correlation for each of the tests presented in Figure 3 bears out a slower adjustment process with this earnings growth pattern with it extending beyond the 13 week trading periods each quarter in the case of test case $2 \mathrm{C}$. This is not surprising as it will be harder for the generated prices to "catch up" where fair value is frequently trending as can be seen in Figure 4 where we plot a slice of our history of the fair value price and the generated prices under test case $2 \mathrm{C}$ where we have $25 \%$ fundamental investors and $75 \%$ index investors..

Table 4: Fundamental and Index Investors (correlated earnings growth)

\begin{tabular}{|c|c|c|c|c|}
\hline \multirow{2}{*}{ Moments } & Fair value & \multicolumn{3}{|c|}{ Returns relative to fair value returns for various test cases: } \\
\cline { 3 - 5 } & prices & 25\% index inv. (2A) & $50 \%$ index inv. (2B) & $75 \%$ index inv. (2C) \\
\hline Mean & 0.000700 & 0.000007 & 0.000007 & 0.000007 \\
\hline Standard dev. & 0.006982 & 0.0202 & 0.00362 & 0.00500 \\
\hline Skewness & 5.18254 & -1.0260 & -2.2241 & -3.2447 \\
\hline Kurtosis & 42.6995 & 20.4372 & 25.6188 & 33.2901 \\
\hline
\end{tabular}


Figure 3: Serial Correlation Patterns with Index Investors (correlated earnings growth)
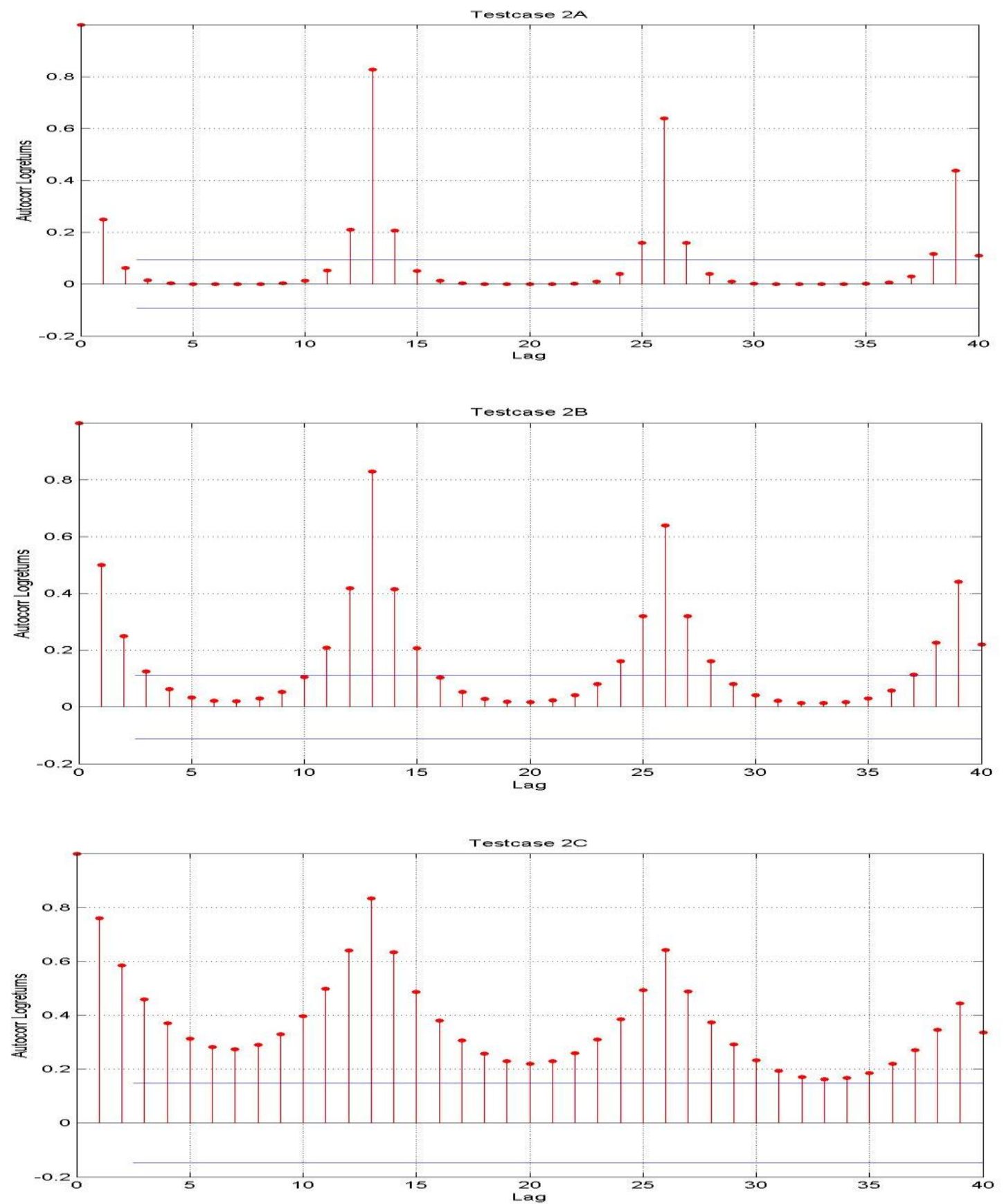
Figure 4: Test Case 2C Price Chart (correlated earnings growth)

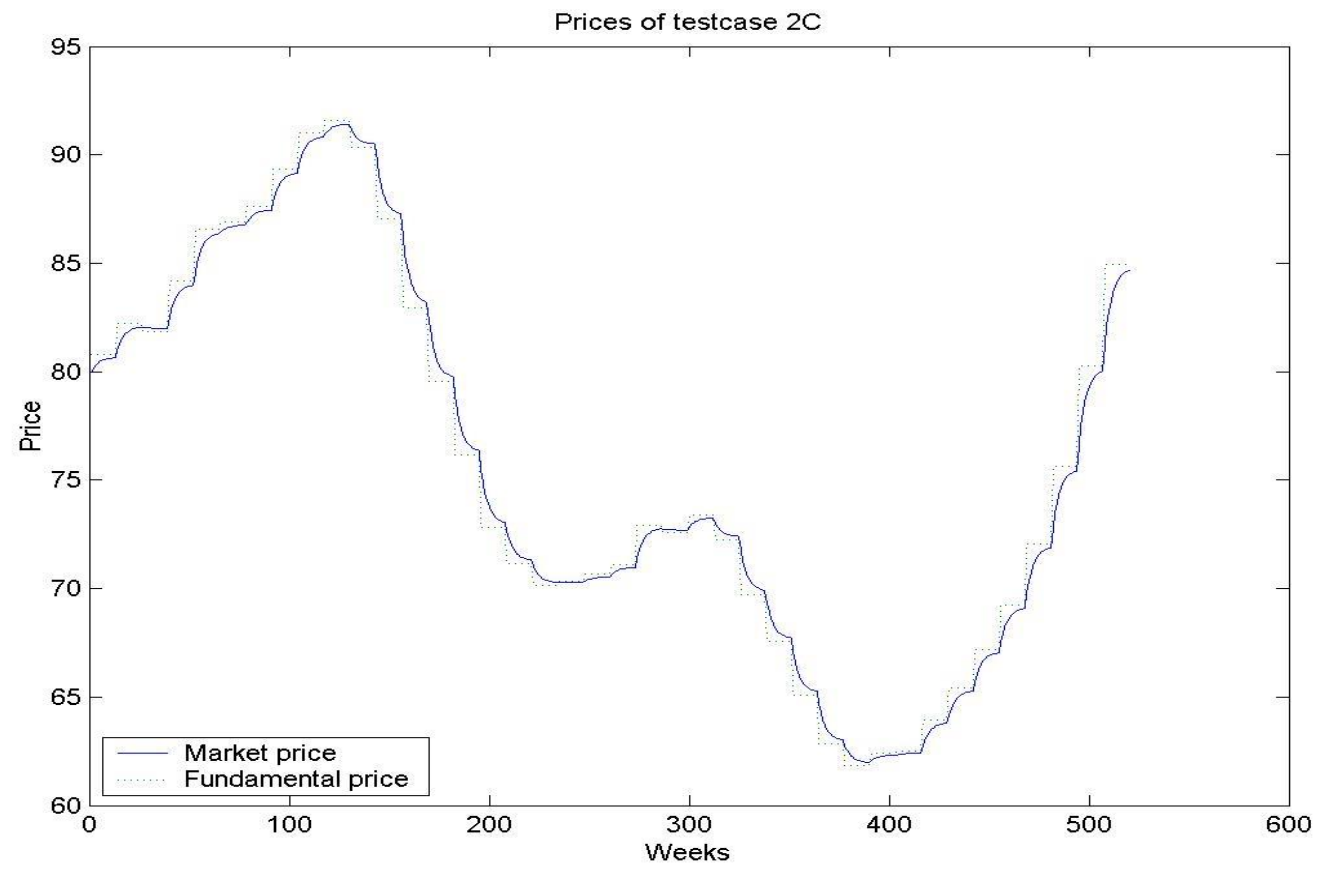

The one clear implication from having a significant proportion of the equity market in the hands of index investors is that is that it slows the speed at which the market adjusts to new information signals. This is not a surprising outcome as index investors are not interested in information signals per se but only in index weights in their pursuit of index returns.

\section{Test Case 3: Fundamental and Momentum Investing}

In test cases $3 \mathrm{~A}, 3 \mathrm{~B}$ and $3 \mathrm{C}$ we examine various combinations of fundamental investing with momentum investing where earnings growth through time is random. We report in Table 5, the moments of the differences in returns between the generated returns and the fair value returns where fundamental and momentum investors represent different combinations of the market. A comparison of the information contained in Table 5 with that in Table 3, where we had index investors, indicates that the introduction of momentum investors has a much greater impact on tracking error to fair value. Again this is not a surprising outcome as the momentum investors pick up on the trend created by the fundamental investors' reaction to new information and so eventually compound the price reaction to this information. This means that in line with Hong and Stein, we get an initial slow reaction to new information when only the fundamental investors react but the momentum investors are attracted by the prolonged price reaction to the information and they eventually drive the price above fair value. In Figure 5, we present that a slice of the price paths and the serial correlation pattern for test case 3B where we have 50\% fundamental investors and 50\% momentum investors. This information highlights the slow initial price adjustment similar to that we saw in the case of index investors but in this case this underreaction is followed by an extended period of price overreaction. 
Table 5: Fundamental and Momentum Investors (random earnings growth)

\begin{tabular}{|c|c|c|c|}
\hline \multirow{2}{*}{ Moments } & \multicolumn{3}{|c|}{ Returns relative to fair value returns for various test cases: } \\
\cline { 2 - 4 } & $25 \%$ momentum (3A) & $50 \%$ momentum (3B) & $25 \%$ momentum (3C) \\
\hline Mean & 0.000007 & 0.000007 & 0.000002 \\
\hline Standard deviation & 0.00208 & 0.00433 & 0.00789 \\
\hline Skewness & -0.6238 & -0.6123 & -0.3083 \\
\hline Kurtosis & 9.8463 & 6.01169 & 3.8657 \\
\hline
\end{tabular}

Figure 5: Test Case 3B Price chart and Correlation Pattern (random earnings growth)
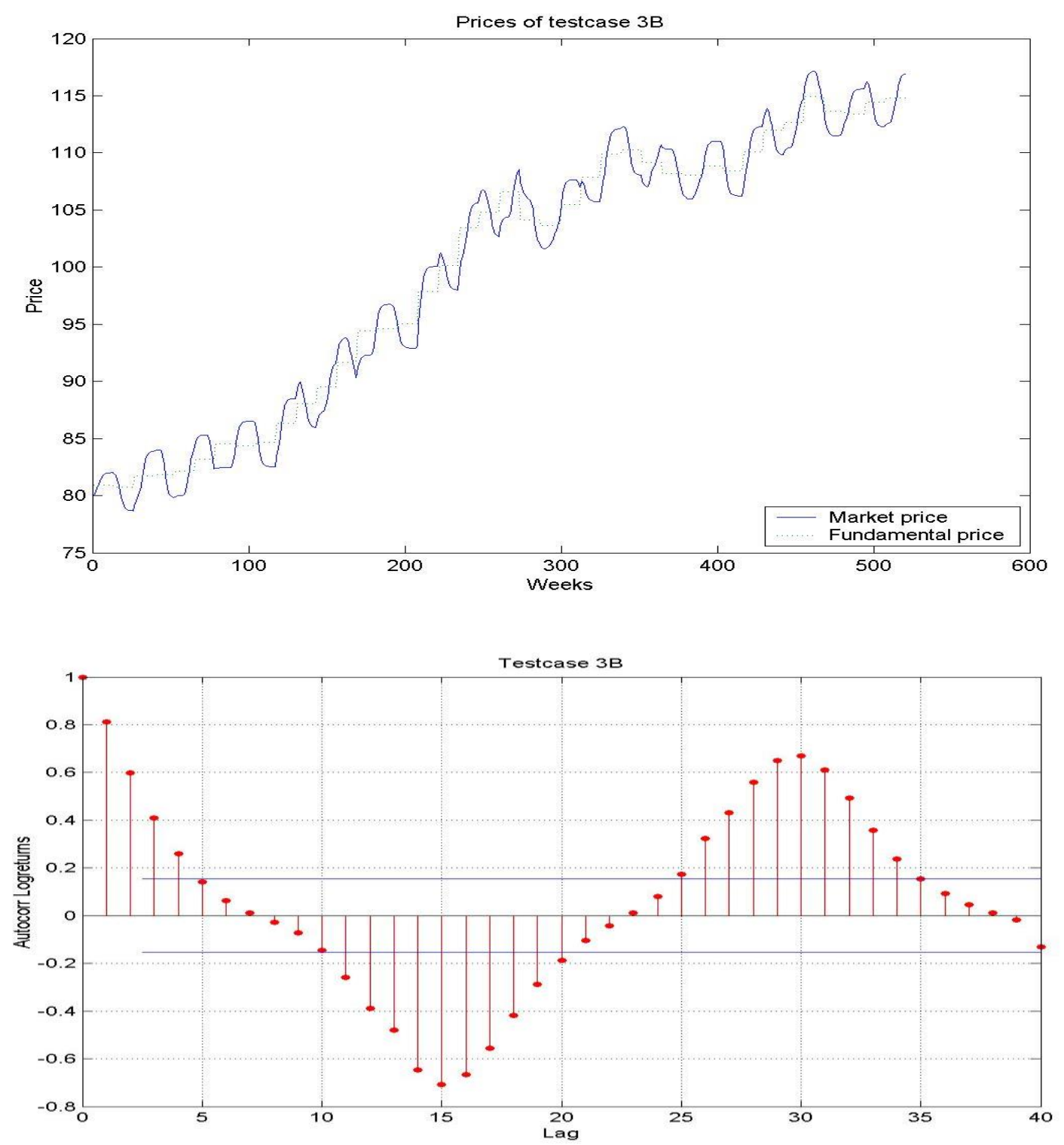
When we introduce serial correlation and mean reversion into earnings growth, we obtain a similar but more extreme version of what we found with random earnings growth. As can be seen from the information contained in Table 6 (compared with Table 5), the volatility in the generated returns around fair value returns actually increases with the advent of more momentum investors, as does the level of the negative skewness and kurtosis. In Figure 6, we present a slice of the price paths and the serial correlation pattern for test case $3 \mathrm{~B}$, where we have $50 \%$ fundamental and $50 \%$ momentum investors. From Figure 5 we see the same pattern of under- and over-reaction to new information as previously when fair value follows a "normal" path (slow upward drift). However where fair value is rising (or falling) at a very fast rate, the pattern of price behaviour becomes more like what we experienced in a market largely composed of index investors. In these cases, the impact of momentum investors is somewhat neutralised by the trading rules that we have used where demand from momentum traders caps out at very high levels of price momentum and where trades are reversed after 13 weeks. A relaxation of one or other of these rules would see even greater oscillations in prices. Indeed, it is interesting to note that even with the maintenance of these rules, we return to a much clearer case of underand over-reaction under test $3 \mathrm{C}$ where momentum investors represent $75 \%$ of the market (see Figure 7). .

Table 6: Fundamental and Momentum Investors (correlated earnings growth)

\begin{tabular}{|c|c|c|c|}
\hline \multirow{2}{*}{ Moments } & \multicolumn{3}{|c|}{ Returns relative to fair value returns for various test cases: } \\
\cline { 2 - 4 } & $25 \%$ momentum (3A) & $50 \%$ momentum (3C) & $75 \%$ momentum (3C) \\
\hline Mean & 0.000008 & 0.000009 & 0.000004 \\
\hline Standard deviation & 0.00234 & 0.00489 & 0.00901 \\
\hline Skewness & -1.1051 & -1.1087 & -0.7194 \\
\hline Kurtosis & 15.4111 & 11.3500 & 6.8385 \\
\hline
\end{tabular}

Figure 6: Test Case 3B Price Chart and Correlation Pattern (correlated earnings growth)

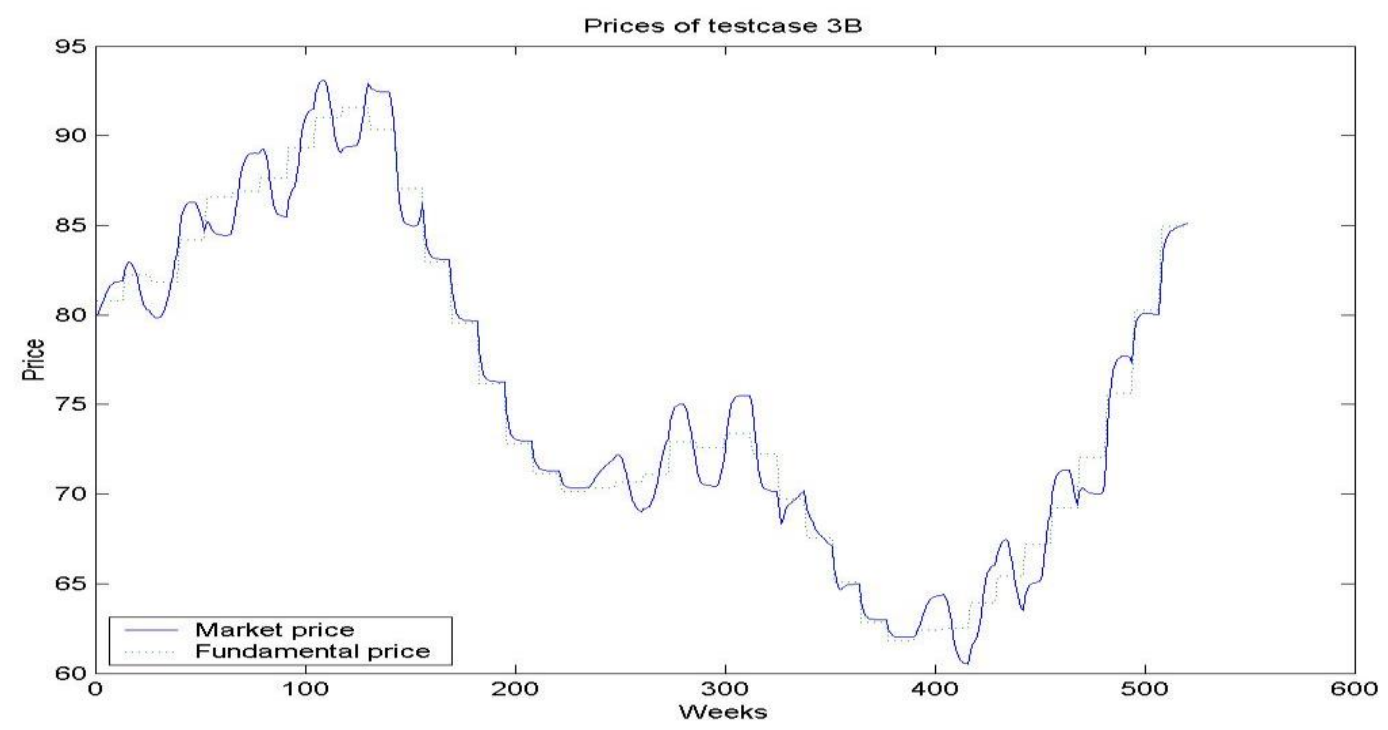




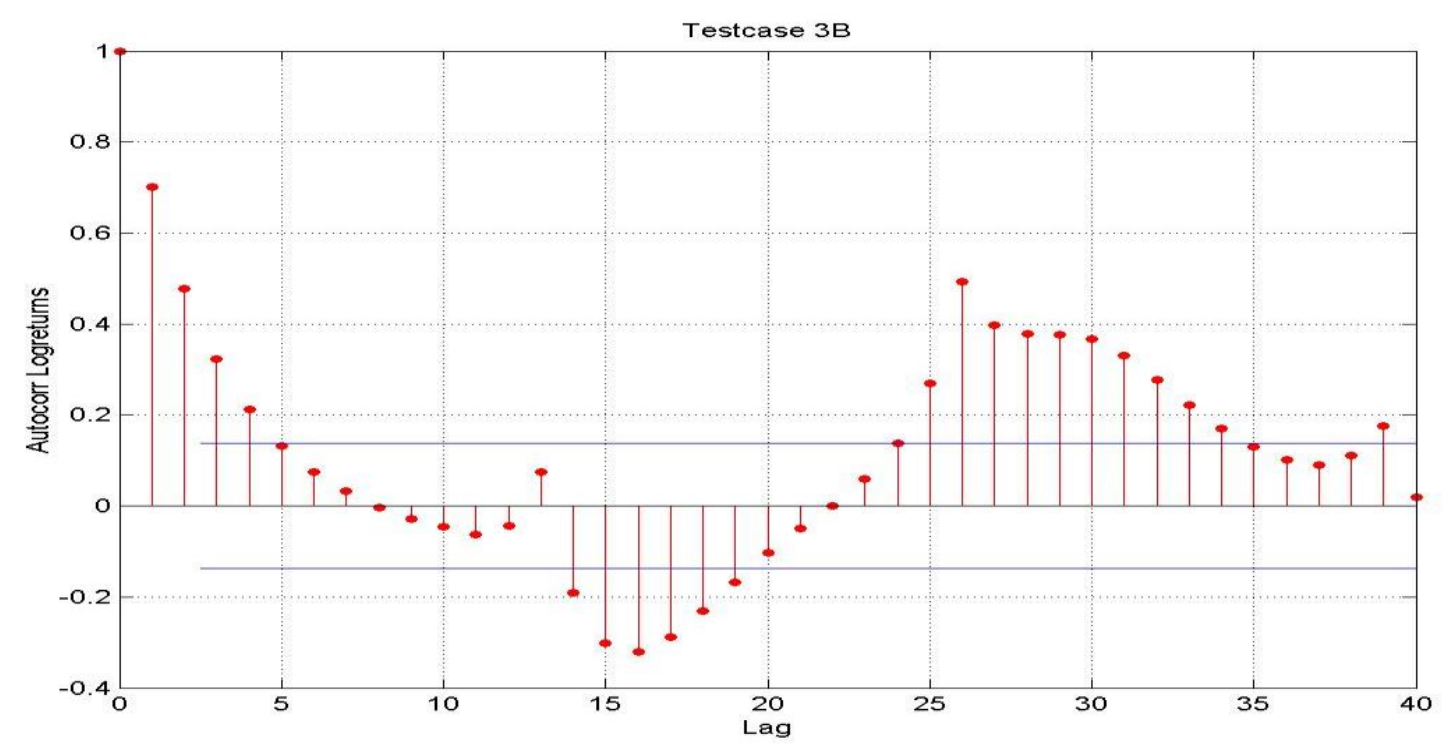

Figure 7: Test Case 3C Price Chart (correlated earnings growth)

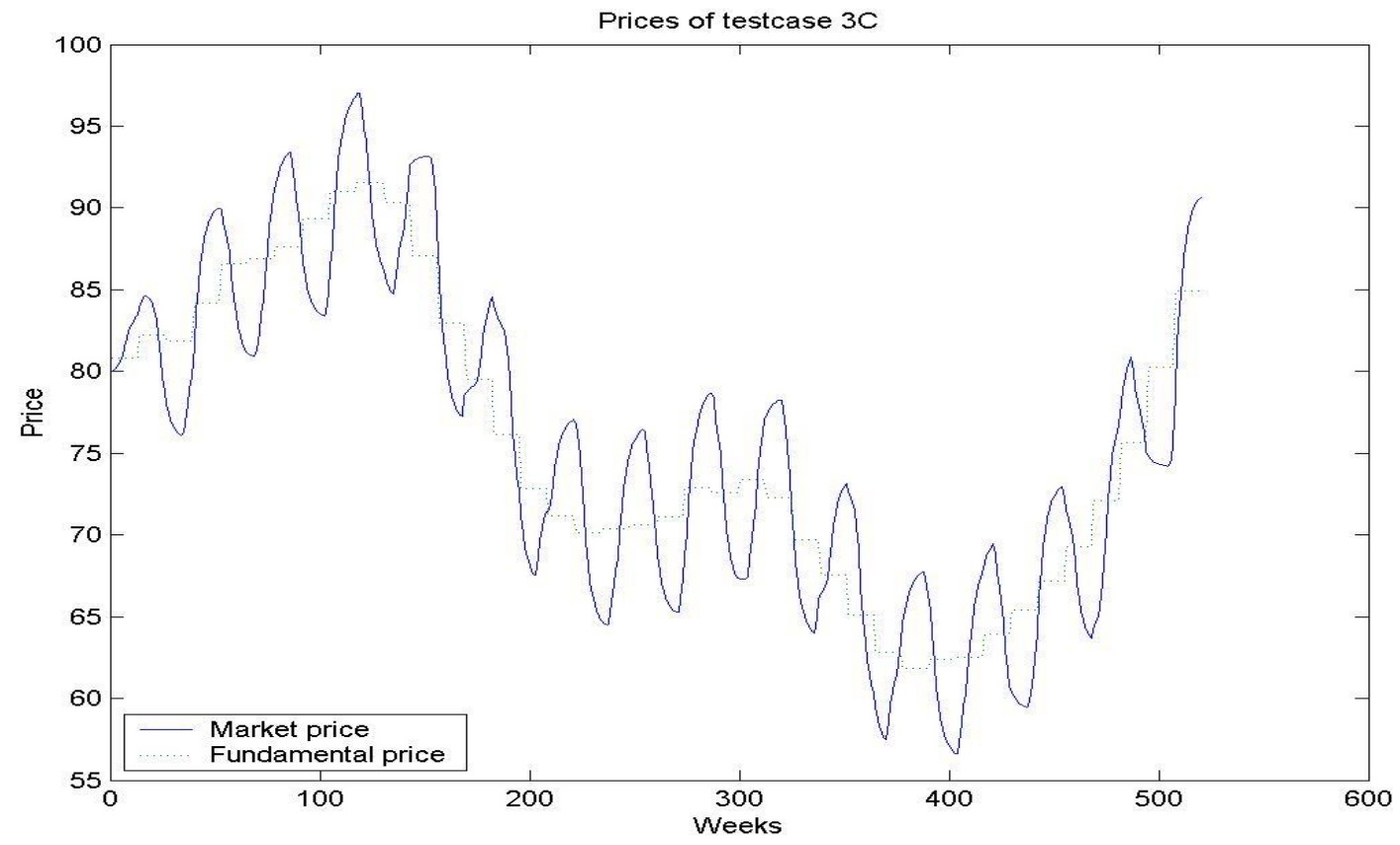


With the advent of momentum investors into our analysis, we see the emergence of a clear pattern of first underreaction and then overreaction to the release of information with the price distortions being even greater once we induce serial correlation into the behaviour of fair value prices. These findings are very consistent with the market behaviour postulated by Hong and Stein in their world where markets were composed of both fundamental investors ("news followers") and momentum investors ("trend followers"). Momentum investors, like index investors, are completely oblivious to the implications for pricing of any news relating to the company. The index investors are also oblivious to any trend established in prices and so their main impact is to slow the price response to any corporate announcement. However, the observation of a price trend will attract the momentum investors whose purchases and sales will then be entirely driven by their investment rules independent of news and so result on most occasions in the prices overshooting fair value.

\section{Test Case 4: Fundamental, Index and Momentum Investing}

Most equity markets today are composed of investors pursuing a diversity of investment styles with fundamental, index and momentum being typically the most prominent. In this section of the paper we consider the pricing implications of various combinations of these three types of investors. In each case, we assume that index and momentum investors represent an equal proportion of the non-fundamental proportion of the market. The moments of the distribution of generated returns relative to the fair value returns are reported in Table 7. As would be expected, the tracking error to fair value increases as the proportion of fundamental investors decrease, taking on values between those found previously when fundamental investors were combined solely with either index or momentum investors. The negative skewness again indicates that prices typically underreact to new information while the kurtosis shows that the tracking of fair value decreases with the proportion of fundamental investors in the market.

In the remainder of the analysis we concentrate on a market composed of one-third of each type of investor, which we believe to be somewhat representative of many equity markets. In Figure 8, we present a slice of the price paths and the serial correlation pattern for test case 4D. An examination of both figures clearly indicates that this mix of investment styles in these proportions clearly leads to pricing that lags fair value in the first instance at the time of an information release. The end outcome is often an overreaction resulting in prices oscillating around fair value but more typically being fairly far removed at any given point in time.

Table 7: Fundamental, Index and Momentum Investors (random earnings growth)

\begin{tabular}{|c|c|c|c|c|}
\hline \multirow{2}{*}{ Moments } & \multicolumn{4}{|c|}{ Returns relative to fair value returns for various test cases: } \\
\cline { 2 - 5 } & $\begin{array}{l}\text { 75\% fundamental, } \\
\begin{array}{c}12.5 \% \text { index and } \\
\text { momentum }\end{array}\end{array}$ & $\begin{array}{l}50 \% \text { fundamental, } \\
25 \% \text { index and } \\
\text { momentum }\end{array}$ & $\begin{array}{l}33.4 \% \text { fundamental, } \\
33.3 \% \text { index and } \\
\text { momentum }\end{array}$ & $\begin{array}{l}\text { 25\% fundamental, 37.5\% } \\
\text { index and momentum }\end{array}$ \\
\hline Mean & 0.000008 & 0.000007 & 0.000007 & 0.000007 \\
\hline $\begin{array}{c}\text { Standard } \\
\text { deviation }\end{array}$ & 0.00176 & 0.003035 & 0.004180 & 0.00489 \\
\hline Skewness & -1.3060 & -1.7470 & -1.5670 & -1.3815 \\
\hline Kurtosis & 14.5911 & 12.2852 & 8.9580 & 8.5926 \\
\hline
\end{tabular}


Figure 8: Test Case 4D Price Chart and Correlation Pattern (random earnings growth)
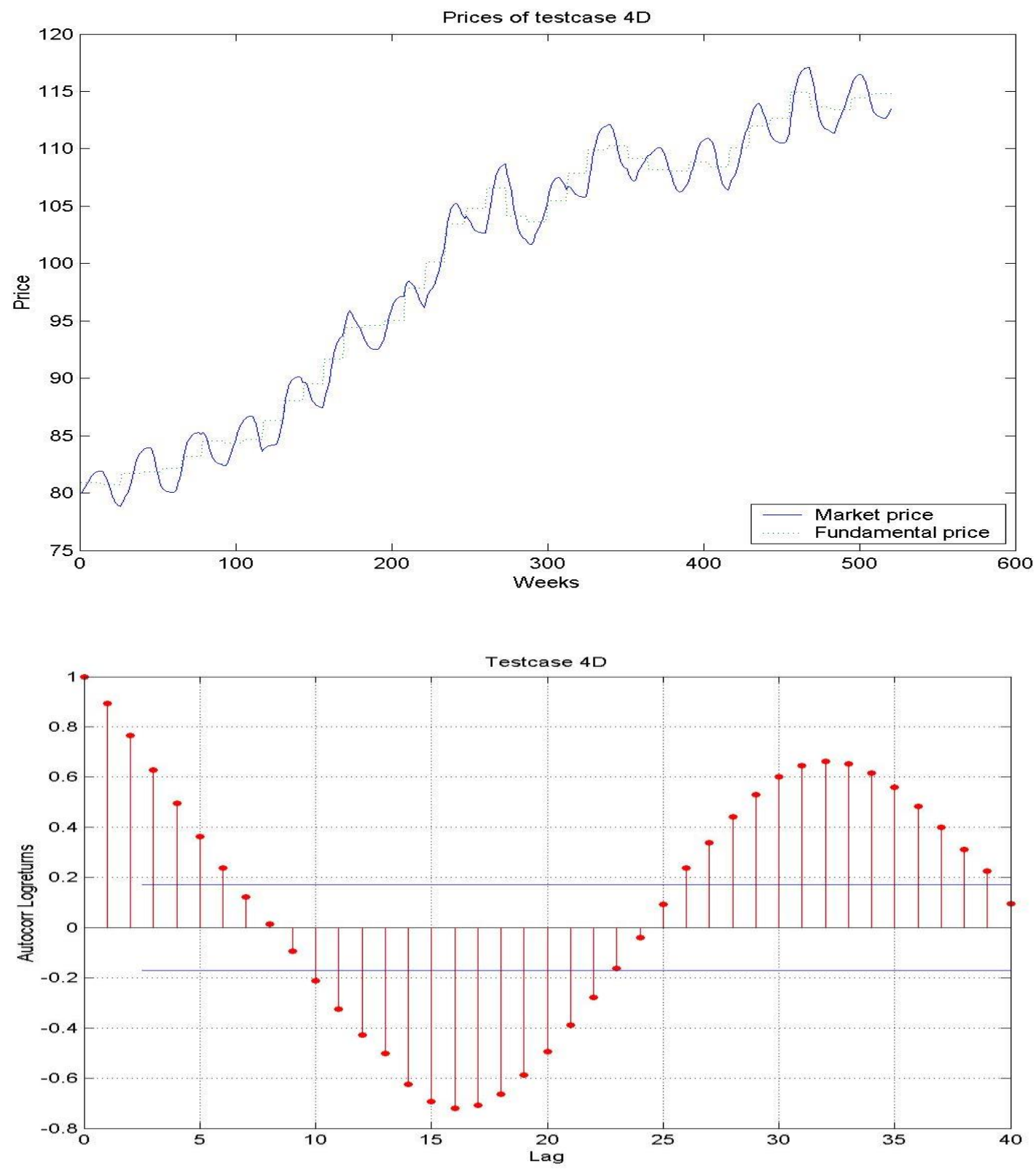

We report in Table 9 the moments of the difference between generated returns and the fair value returns where the earnings growth is assumed to first trend and then mean revert. We see that here the tracking of generated prices to fair value is more volatile than is the case when earnings growth is random. The impact on the other moments is to slightly increase the negative skewness and kurtosis. We present in Figure 8 an illustrative series of price movements to fair value for the test case where each of the three styles control onethird of the market and then the correlation structure in log prices for this same test case across all simulations. When we look at the generated prices through time relative to fair value, we see a similar pattern to what we saw when looking at combinations of fundamental and momentum investors. The generated prices oscillate around fair value when fair value is drifting slowly (typically upwards). However when it is rapidly moving in either direction, the generated prices tend to chase fair value. The pattern of the serial correlations is interesting in that we see a slow reaction to the initial information as evidence in the correlations diminishing over longer lags within the 13 week cycle. In the case where earnings growth is random, this was followed by clear evidence of overshooting as these correlations became negative which was all consistent with a pattern of first underreaction and then overreaction. Now with a path of trending and then mean reversion built into earnings, this pattern is interrupted with the initial underreaction tapering off 
and then followed by another short period of underreaction before we have the period of overreaction. This pattern is consistent with the correction to an overreaction frequently being interrupted by another announcement similar to the previous one (e.g. good news following good news). It also reflects a mixture of cases with oscillation during more normal periods with extended trends during periods when the stock is moving rapidly in one direction or the other.

Table 8: Fundamental, Index and Momentum Investors (correlated earnings growth)

\begin{tabular}{|c|c|c|c|c|}
\hline \multirow{2}{*}{ Moments } & \multicolumn{4}{|c|}{ Returns relative to fair value returns for various test cases: } \\
\cline { 2 - 5 } & $\begin{array}{l}75 \% \text { fundamental, } \\
12.5 \% \text { index and } \\
\text { momentum }\end{array}$ & $\begin{array}{l}50 \% \text { fundamental, } \\
25 \% \text { index and } \\
\text { momentum }\end{array}$ & $\begin{array}{l}33.3 \% \text { in each of } \\
\text { fundamental, index } \\
\text { and momentum }\end{array}$ & $\begin{array}{l}25 \% \text { fundamental, } \\
37.5 \% \text { index } \\
\text { momentum }\end{array}$ \\
\hline Mean & 0.000008 & 0.000008 & 0.000008 & 0.000007 \\
\hline Standard dev & 0.00220 & 0.00388 & 0.00522 & 0.00605 \\
\hline Skewness & -1.3795 & -2.0052 & -2.1129 & -1.9955 \\
\hline Kurtosis & 18.6924 & 21.2576 & 18.6250 & 17.6924 \\
\hline
\end{tabular}

Figure 9: Test Case 4D Price Chart and Correlation Pattern (correlated earnings growth)
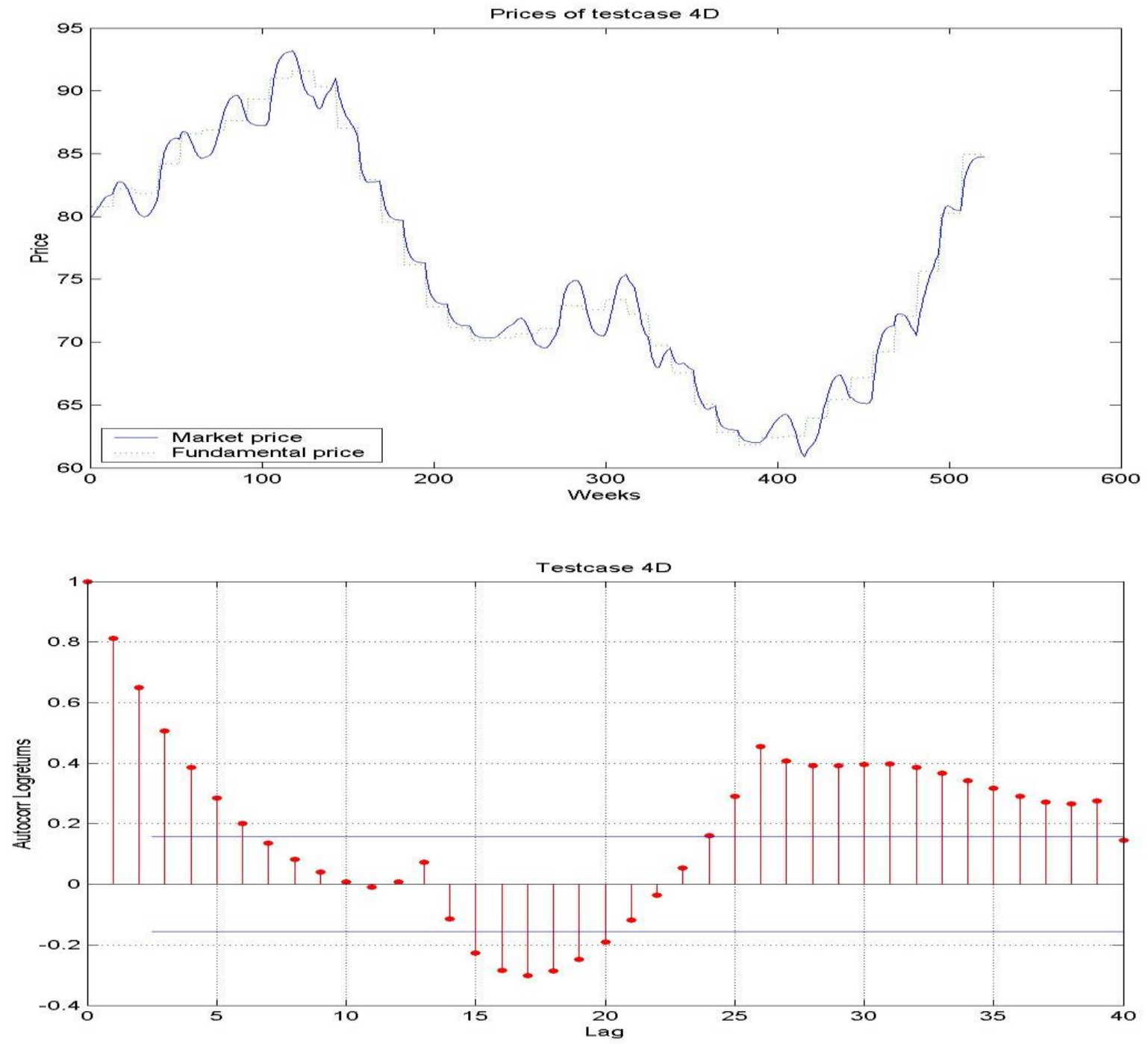


\section{Summary of Test Findings}

The simulations from our models have provided us with some very useful insights into market behaviour with various combinations of our three types of investors:

- confirmation that a market largely composed of fundamental investors will result in a high level of market efficiency in that prices will quickly react to the release of new information,

- index investors will progressively slow this reaction to new information as they come to represent an increasing proportion of the market,

- momentum investors (similar to index investors) will slow the market reaction to new information but will invest when a drift in prices becomes established, which eventually leads to an overreaction.

We did see instances where momentum investors did cause an overreaction in prices in those cases where prices were rapidly moving in one direction as during these periods the generated prices by our model were largely trying to keep up with the movements in fair value. This finding somewhat reflects the conservative modelling of the momentum investors whose demand was capped and who were also assumed to reverse their transactions after a 13-week holding period.

The results that we find using what we believe to be realistic combinations of the three types of investors are consistent with the Hong and Stein explanation for why we see both underreaction and overreaction occurring within equity markets. The length and extent of the deviations from fair pricing would appear to be much less than that which is actually observed in markets. However this is largely a function of two characteristics of our model:

- the way that we model each investor type and particularly the conservative nature of our momentum investor, and

- the fact that we have only one information source occurring at regular intervals whereas the actual market is subjected to a bevy of information shocks happening at irregular intervals ${ }^{9}$

\section{Section 5: Summary and Concluding Comments}

We have seen a plethora of evidence that has been either supportive of, or in conflict with, market efficiency over the last 50 years and much discussion of the degree to which securities are efficiently priced across a whole range of markets. During this same period we have seen very little discussion as to the extent to which these conditions on which market efficiency is dependent are actually met within these markets. For example, there is much evidence in the US of manipulation by management of both market expectations and also reported profit during the late 1990's. This behaviour certainly has been shown to have consequences for pricing and so could bring into question the efficiency the pricing within the US equity markets during this period. Another factor that has implications for market efficiency, and the one which has been the focus in this paper, is the composition of investment style within markets. In order for securities to be fairly priced it is necessary for sufficient investors to be trying to detect mispriced stocks with the intention of profiting by trading to exploit any identified mispricings. However, more recently, we have seen an increasing proportion of investment funds being managed following styles, such as index and momentum investing, where information and fair pricing are irrelevant to the decision process. We simulated the pricing behaviour within markets with various compositions of fundamental, momentum and index and found that they exhibited behaviour quite consistent with that found in much of the market anomalies literature.

The findings in this paper re possible inefficiencies in security pricing within equity markets has significant implications for the allocative efficiency within these markets and thus for the efficiency of the related economies. The most recent instance of this has been during the bubble of the late 90's where much scarce

\footnotetext{
${ }^{9}$ The fact that we have only a limited number of information shocks also goes a long way to explaining why the volatility in our prices are much lower than those in actual equity markets.
} 
capital was wasted by the investment behaviour of firms that had particularly easy access to new capital during this period. We would maintain that a major factor contributing this outcome has been due to the influence that index and momentum investors, not only in terms of the effect that they had on prices but also because they were easy prey for those firms wishing to raise new capital. An important question is if this has happened once will it happen again? Our response would be that we do not see ant reason why not based on our expectations that index and/or momentum investing will continue to prove attractive to a large proportion of investors. This being the case, one might expect to see a continuation of inefficient pricing within markets which will again reach extreme levels during times of excessive market euphoria.

One might say that index and momentum investors are bad for the economy but good for individual investors. This, in turn, raises the question as to what Governments might do about what may prove to be another extremely important instance of market failure? The answers to this question are far from obvious as it is difficult to see Governments using their fiscal and/or legislative powers to discriminate against one investment style in favour another. The solution might come from another source with the market developing other types of securities, such as GDP-linked bonds, which might cause investors to be to weaned off equities and so alleviate the problem ${ }^{10}$.

We believe that the matters that we have raised open up many other areas of fruitful research, some of which we plan to address using an extended version of the model that we have developed in this paper. For example, we plan to introduce other forms of investing such as contrarians and "noise traders" to evaluate the impact that they might have on pricing behaviour. In addition we want to more closely track the profitability of the different investment styles through a market cycle and then allow for a drift in investors towards those styles that have more recently been displaying the best performance. There are an almost limitedless number of areas that could be addressed and we look forward to communicating some of the more interesting findings in future papers and reading the associated work of other authors.

\section{References}

Barberis, N., Shleifer, A. and Vishny, R. 1998. A Model of Investment Sentiment, Journal of Financial Economics, 49, 3.

Burch, T. and Swaminathan, B. 2001, Are Institutions Momentum Traders? Working Paper: School of Business Administration, University of Miami.

Chan, K., Chan, L., Jegadeesh, N. and Lakonishok, J. 2001, Earnings Quality and Stock Returns, NBER Working Paper W8308.

Daniel, K., Hirshleifer, D and Subrahmanyam, A. 199Investor Psychology and Security Market Over- and Under-reactions. Journal of Finance, 53, 6.

De Bondt, W. and Thaler, R. 1985. Does the Stock Market Overreact? Journal of Finance, 40, 3.

De Long, J., Shleifer, A., Summers, L., and Waldman, R. 1990. Positive Feedback Investment Strategies and Destabilizing Rational Speculation, Journal of Finance, 45, 2.

Fama, E. 1970, Efficient Capital markets: A Review of Theory and Empirical Work, Journal of Finance, 37 , 2.

Fama, E. 1998. Market Efficiency, Long-term Returns, and Behavioral Finance, Journal of Financial Economics, 49, 3.

Foster, G., Ohsen, C. and Shevlin, T. 1984. Earnings Releases, Anomalies, and the Behavior of Security Returns. Accounting Review, 59

Grossman, S. and Stiglitz, J. 1980. On the Impossibility of Informationally Efficient Markets, American Economic Review, 70, 3.

\footnotetext{
${ }^{10}$ For a discussion of this possibility, see Woolley [2003]
} 
Harris, S.2004. The Long-term Performance of UK Stocks After Making Rights Issues, Journal of Asset Management, forthcoming

Hong, H and Stein, J. 1999. A Unifies Theory of Underreaction, Momentum Trading, and Overeaction in Asset Markets, Journal of Finance, 54, 6.

Ikenberry, D., Lakonishok, J. and Vermaellen, T. 2000. Stock Repurchases in Canada: Performance and Strategic Trading, Journal of Finance 55, 5.

Jegadeesh, N. and Titman, S. 2001. Profitability of Momentum Strategies: An Evaluation of Alternative Explanations, Journal of Finance. 56, 2.

Jegadeesh, N., Kim, J., Krische, SD, and Lee, CM. 2004. Analyzing the Analysts: When Do Recommendations Add Value? Journal of Finance, forthcoming

Kadiyala, P. and Rau, P 2002. Investor Reaction to Corporate Event Announcements: Under-reaction or Over-reaction?, Journal of Business

Lakonishok, J., Shleifer, A., and Vishny RW. 1994. Contrarian investments, extrapolation, and risk, Journal of Finance: 49, 5.

Lee, C. 2001. Market Efficiency and Accounting Research: A Discussion of 'Capital Market Research in Accounting' by S. P. Kothari. Journal of Accounting and Economics, 31, 1-3.

Lorie, J. and Hamiltion, M. 1973. The Stock Markets: Theory and Evidence, Richard D. Irwin, Homeland, Il.

Malkiel, B. 2003. Passive Investment Strategies and Efficient Markets, European Financial Management, 9, 1 .

Rubinstein, M, 2001. Rational Markets: Yes or No? The Affirmative Case, Financial Analysts Journal, $57,3$. Siegel, J. What is an Asset Bubble? An Operational Definition. European Financial Management, 9, 1.

Sloan, R. 1996. Do Stock Prices Fully Reflect Information in Accrual and Cash Flows about Future Earnings? Accounting Review, 71, 3.

Smith, C. 1986. Raising Capital: Theory and Evidence. Midland Corporate Finance, 4, 4.

Soffer, L. and Walther, B. 2000. Return Momentuum, Return Reversals and Earnings Surprise. Working Paper: University of Illinois at Chicago

Woolley, P. 2003. Stock Market Dysfunctionality and the Case for GDP Bonds, Mimeo: GMO London.

Woolley, P. and Bird 2003, R., Economic Implications of Passive Investing. Journal of Asset Management, 3 , 4. 